\title{
RESENHA*
}

\section{Umberto Paulini**}

\begin{abstract}
RESUMO
A presente resenha tem por objetivo apresentar ao leitor, de forma resumida, o conteúdo do artigo Norme costituzionali e rapporti di diritto civile, publicado por Pietro Perlingeri, em sua obra Scoule, tendenze e metodi. O texto é pioneiro no estudo do direito civil-constitucional e, a despeito do lançamento do livro "Perfis do Direito Civil”, ainda não possui tradução específica para o português. A resenha está centrada na análise do papel das normas constitucionais nas relações privadas. Parte-se da crítica à compreensão das normas que regulam o Direito Civil como portadoras de significado autônomo, expressão de um sistema completo e totalmente fechado. Num segundo momento, estuda-se o influxo das normas constitucionais na atividade hermenêutica, nos conteúdos e nos significados das normas de nível ordinário para, posteriormente, atentar-se para a possibilidade de sua aplicação direta nas relações interprivadas. São expostos os reflexos deste pensamento no sistema de controle de constitucionalidade italiano e, em seguida, examinadas experiências similares em outros ramos do conhecimento jurídico. Concluí-se, ao final, que um amplo e sugestivo programa de investigação foi aberto ao estudioso do Direito Civil, cabendolhe agora explorá-lo.

Palavras-chave: Pietro Perlingeri; Constitucionalização; Direito Civil; Aplicação; Normas Constitucionais; Relações Privadas.
\end{abstract}

Sumário: CONSIDERAÇÕES PRELIMINARES; $\mathbf{1}$ NECESSIDADE DE
ESCLARECIMENTO SOBRE O SIGNIFICADO DA RELEITURA CONSTITUCIONAL DA
LEGISLAÇÃO ORDINÁRIA. NATUREZA JURÍDICA, NÃO POLÍTICA, DA NORMA
CONSTITUCIONAL E SEU PAPEL NA TEORIA DAS FONTES NORMATIVAS; 2
AMBIGÜIDADE E DEFEITO DE GENERALIZAÇÃO NA COMPREENSÃO DA NORMA
CONSTITUCIONAL COMO LIMITE DA NORMA ORDINÁRIA: OS ENUNCIADOS
NORMATIVOS ORDINÁRIOS SERIAM EXPRESSÃO DE UM SISTEMA FECHADO E
APARTADO; 3 A NORMATIVA CONSTITUCIONAL COMO EXPRESÃO DE
PRINCÍPIOS JURÍDICOS GERAIS ASSUME VALOR EM SEDE DE INTERPRETAÇÃO
DOS ENUNCIADOS NORMATIVOS ORDINÁRIOS. EXCLUSÃO DE UMA POSIIVEL
OBJEÇÃO DIANTE DA HIERARQUIA DOS INSTRUMENTOS HERMENÊUTICOS

* Texto base: PERLINGERI, Pietro. Norme costituzionali e rapporti di diritto civile. In.: Scoule, tendenze e metodi: problemi di diritto civile. Nápoles: ESI, 1989. p. 109-134.

** Mestrando em Direito das Relações Sociais pela UFPR. 
PREDISPOSTA NO ART. 12 DAS DISPOSIÇÕES PRELIMINARES AO CÓDIGO CIVIL. DINAMICIDADE E HISTORICIDADE DO ORDENAMENTO: INTERPRETAÇÃO LÓGICO-SISTEMÁTICA E VALORES CONSTITUCIONAIS; 4 A NORMATIVA CONSTITUCIONAL COMO JUSTIFICAÇÃO DA NORMA ORDINÁRIA. PERIGO DA CONSTITUCIONALIZAÇÃO DE TODOS OS RAMOS DO DIREITO E MITIGAÇÃO DAS TRADICIONAIS REGRAS HERMENÊUTICAS. CONTRAPONTO: SIGNIFICADO E EXTENSÃO DO PRINCÍPIO DA LEGALIDADE CONSTITUCIONAL COMO EXIGÊNCIA DE UNIDADE DO ORDENAMENTO E DE SUAS FONTES NORMATIVAS; AS REGRAS HERMENÊUTICAS COMO EXPRESSÃO DA ESTRUTURA E DA LÓGICA DO SISTEMA JURÍDICO, NÃO DA ABSTRATA LÓGICA DO JURISTA; 5 O PROBLEMA DA DIRETA RELEVÂNCIA DAS NORMAS CONSTITUCIONAIS NAS RELAÇÕES INTERPRIVADAS. A APLICAÇÃO INDIRETA VIA NORMA ORDINÁRIA SE TRADUZ, SEGUNDO O ESQUEMA LÓGICO DO COMBINADO / DISPOSTO, EM UMA APLICAÇÃO COMBINADA: NÃO MERA ATIVIDADE INTERPRETATIVA DOS ENUNCIADOS ORDINÁRIOS, MAS ATIVIDADE DE INDIVIDUAÇÃO DA MESMA NORMATIVA; 6 COMPATIBILIDADE DO ASSUNTO COM A EXCLUSIVIDADE ATRIBUÍDA À CORTE CONSTITUCIONAL EM TEMA DE CONTROLE DE CONSTITUCIONALIDADE DOS ATOS COM FORÇA DE LEI E DA SUA POSSIBILIDADE DE ELIMINAÇÃO. UTILIDADE DA NORMA CONSTITUCIONAL NA VALORAÇÃO DISCRICIONÁRIA DO JUIZ E DO INTÉRPRETE. PLANO DIVERSO: CADA UM SE JUSTIFICA POR UMA PRECÍPUA FUNÇÃO; 7 CONFIRMAÇÃO DESTA PERSPECTIVA EM ALGUMAS SIGNIFICATIVAS ORIENTAÇÕES JURISPRUDENCIAIS E DOUTRINÁRIAS. ACENO AO DIREITO DO TRABALHO, AO DIREITO PENAL, AO DIREITO PROCESSUAL CIVIL E PENAL. FATTISPECIE CIVILÍSTICA NA UTILIZAÇÃO DIRETA DA NORMA CONSTITUCIONAL SEJA EM PRESENÇA, SEJA EM AUSÊNCIA DE ESPECÍFICA DISCIPLINA ORDINÁRIA; 8 RELEVOS CONCLUSIVOS, ÚTEIS À SUPERAÇÃO DA TRADICIONAL CONTRAPOSIÇÃO ENTRE DIREITO PÚBLICO E DIREITO PRIVADO E PARA FUNDAÇÃO DO DIREITO CIVIL-CONSTITUCIONAL.

\section{CONSIDERAÇÕES PRELIMINARES}

A idéia de que os velhos institutos do Direito Privado adquirem um novo sentido em face dos contornos que lhes são oferecidos pelas normas constitucionais, conquanto de desenvolvimento relativamente recente no Brasil, traduz a mais notável preocupação dos civilistas nos últimos tempos. Autores da melhor linhagem - como, por exemplo, Luiz Edson Fachin, Gustavo Tepedino, Maria Celina Bodin de Moraes e Paulo Luiz Netto Lôbo - incorporaram os princípios basilares de tal reflexão, nascidos principalmente na doutrina italiana, difundindo a temática e oferecendo suas próprias contribuições. Atualmente, a matéria ganha novo fôlego com a discussão sobre a 
eficácia dos direitos fundamentais nas relações entre particulares que, segundo Ingo Wolfgang Sarlet, é apenas um capítulo de uma seara teórica maior, denominada "Constitucionalização do Direito Civil". Dada a indiscutível relevância do assunto, propõe-se, então, escrever uma recensão de um artigo primoroso publicado pelo mestre Pietro Perlingeri, na obra "Scoule, tendenze e metodi".

\section{NECESSIDADE DE ESCLARECIMENTO SOBRE O SIGNIFICADO DA RELEITURA CONSTITUCIONAL DA LEGISLAÇÃO ORDINÁRIA. NATUREZA JURÍDICA, NÃO POLÍTICA, DA NORMA CONSTITUCIONAL E SEU PAPEL NA TEORIA DAS FONTES NORMATIVAS}

Ao final dos anos sessenta, os civilistas italianos adentravam a "releitura do Código Civil e das leis especiais à luz da Constituição Republicana", uma metodologia comprometida com a adequação de categorias e conceitos com as exigências da sociedade conflitual e participativa, em constante transformação. Partiu-se da constatação de que os institutos do Direito Civil assumiam conteúdos e significados diversos, seja pela intervenção reformadora do legislador, seja pela imposição de numerosas e sutis questões de legitimidade constitucional.

Mas essa empresa caminhou sem ritmo, devido à ausência de uma adequada reflexão acerca do complexo papel que, na teoria das fontes normativas do Direito Civil, assume a Carta Fundamental e, em particular, por força da lacuna doutrinária no que diz respeito a uma pontual individuação da relevância das normas e princípios constitucionais nas relações concretas. Assim, a fórmula da releitura constitucional da legislação ordinária necessita de um esclarecimento, evitando que assuma um significado ambíguo.

Para tal fim, é indispensável superar a perplexidade com que se deparam inúmeros posicionamentos doutrinários, ao tratar da natureza - não meramente política, mas, por excelência, jurídica - das normas constitucionais. Portanto, é preciso, de um lado, sublinhar a posição de supremacia da Constituição na hierarquia 
das fontes normativas; de outro lado, individuar, com uma rigorosa operação hermenêutica, a hierarquia dos valores caracterizantes da filosofia constitucional. A natureza rígida da Constituição e sua supremacia, no nível das fontes, induzem a atribuir natureza jurídica aos enunciados de que é constituída.

Quanto aos valores que são o fundamento do ordenamento, esses são individuáveis mediante uma correta interpretação histórico-sistemática da Carta Fundamental, da qual emerge indiscutivelmente a centralidade da pessoa humana e de seu livre desenvolvimento em relação às situações patrimoniais. A perspectiva existencial, fulcrada na dignidade da pessoa humana, prevalece sobre a perspectiva produtivística e a iniciativa privada é inibida quando se desenvolve da maneira a produzir dano à segurança, à liberdade ou à dignidade humana. Logo, é indiscutível que os valores existenciais constituem o fundamento do ordenamento, incidem sobre o sistema jurídico como um todo, sobre todos os seus institutos, até mesmo aqueles mais técnicos e aparentemente neutros.

E, para compreender "como" e "de que maneira" esta incidência é possível, faz-se mister individuar corretamente a relação existente entre as normas constitucionais e as normas ordinárias, bem como o significado da prevalência das primeiras sobre as segundas. Sobre o assunto, a doutrina assume diversas posturas. 


\section{AMBIGÜIDADE E DEFEITO DE GENERALIZAÇÃO NA COMPREENSÃO DA NORMA CONSTITUCIONAL COMO LIMITE DA NORMA ORDINÁRIA: OS ENUNCIADOS NORMATIVOS ORDINÁRIOS SERIAM EXPRESSÃO DE UM SISTEMA FECHADO E APARTADO}

Uma primeira vertente de pensamento concebe a norma constitucional como "limite" ou "barreira" à norma ordinária. Os enunciados normativos ordinários, enquanto não ofendem um interesse constitucionalmente protegido, assumem autonomamente significado e fundamento, como expressão de um sistema completo e totalmente fechado. Nesse sentido, a norma constitucional atua excepcionalmente e de forma residual, sem incidir sobre a atividade interpretativa dos enunciados normativos ordinários. Este posicionamento aparenta indicar uma separação entre normas ordinárias e normas constitucionais: estas últimas, externas no confronto com as primeiras, admitindo-se, portanto, a existência de dois sistemas apartados. Tal configuração se adapta, sem dificuldade, à cultura jurídica dominante, em particular aos cultores do Direito Civil, e consente em conservar íntegro, não apenas na letra da lei, mas também na função e no fundamento, grande parte do corpo de Direito Privado.

A essa concepção se opõe pelo seguinte motivo: não se pode negar que existem normas constitucionais que se propõem a estabelecer limites às normas ordinárias, mas que esta seja, por definição, a única função das normas constitucionais, pode-se certamente contestar. Isto porque, o mecanismo da reserva de lei ora estabelece ao legislador ordinário um limite ou restrição a um direito, ora um comando para o adimplemento de prestações pessoais e patrimoniais. Contudo, a proposta criticada olvida os aspectos promocionais da norma constitucional, dificilmente se adaptando à heterogeneidade de situações subjetivas complexas nas quais estão sempre presentes aspectos de obrigatoriedade.

Ademais, o destinatário da norma constitucional seria, privilegiadamente, o legislador. Por isso mesmo, o recurso à noção de limite impede que a norma constitucional possa ser utilmente reconhecida como verdadeira norma por parte dos operadores jurídicos. Seria consentido a estes tão somente interpretar e aplicar a norma ordinária mediante o esquema lógico da subsunção, com a reserva, todavia, de 
excepcionar, nos limites e nas modalidades previstas, o seu defeito de inconstitucionalidade.

Logo, esta primeira tendência propugna, equivocadamente, a leitura separada do Código e das leis especiais em relação à Carta Fundamental, excepcionalmente e incidentalmente confluentes na exclusiva tentativa de eliminação da norma ilegítima, mediante o incidente de inconstitucionalidade.

\section{A NORMATIVA CONSTITUCIONAL COMO EXPRESSÃO DE} PRINCÍPIOS JURÍDICOS GERAIS ASSUME VALOR EM SEDE DE INTERPRETAÇÃO DOS ENUNCIADOS NORMATIVOS ORDINÁRIOS. EXCLUSÃO DE UMA POSSÍVEL OBJEÇÃO DIANTE DA HIERARQUIA DOS INSTRUMENTOS HERMENÊUTICOS PREDISPOSTA NO ART. 12 DAS DISPOSIÇÕES PRELIMINARES AO CÓDIGO CIVIL. DINAMICIDADE E HISTORICIDADE DO ORDENAMENTO: INTERPRETAÇÃO LÓGICO-SISTEMÁTICA E VALORES CONSTITUCIONAIS

Em outra perspectiva, diversa operacionalidade é atribuída à prevalência da normativa constitucional sobre a ordinária, reconhecendo-se, na primeira, uma expressão de princípios gerais a serem utilizados em sede de interpretação de enunciados normativos ordinários. Deste modo, as opções feitas, no plano normativamente superior, refletem-se na atividade hermenêutica, nos conteúdos e nos significados das normas de nível ordinário. Esta concepção é antitética com relação à precedente porque, movimentada pela exigência de atuação da legalidade constitucional, é capaz de adequar os instrumentos hermenêuticos com a exigência primária de atuação dos valores fundamentais.

A tal escopo não constitui obstáculo o artigo 12 das disposições preliminares do Código Civil italiano que consente o recurso aos princípios gerais do ordenamento jurídico como remédio subsidiário em relação à possível aplicação de uma "precisa disposição" e do recurso à analogia legis. Isto seria situar-se fora da legalidade constitucional. Uma interpretação por graus (primeiro a literal, depois, a analógica, e 
assim por diante) não é aceitável, pois não se adapta à concepção de direito na legalidade constitucional. Perde sentido a referência à "precisa disposição", devendose sempre operar sobre as normas um controle de valor dentro do sistema, controle que exige a individuação de uma ratio iuris normativa, em harmonia e em conformidade com o sistema.

Certamente, o caráter sistemático da interpretação, que encerra em si a própria atividade cognitiva, enquadrando cada normativa no panorama geral do ordenamento, deve inspirar-se nas normas constitucionais. Isto impede que prevaleça a letra da lei, que se utilize uma idéia superada de espírito da lei, que se atribua à lei um juízo de valor discricionário e subjetivo; o interprete terá, na norma constitucional, um ponto firme no qual deverá se apoiar.

Não procede também a crítica de que no critério de interpretação sistemática das disposições legais há um perigo de mutação contínua do ordenamento, porque a dinamicidade e a historicidade são características essências do sistema, sem as quais este perde seu potencial de impacto na realidade concreta. Sem parar sobre a disposição isolada, é preciso lê-la, conhecê-la na lógica do sistema, mesmo que isto requeira inteligência, equilíbrio e sensibilidade particulares. E ainda que isto não garanta a suma coerência do sistema, a atividade jurídica deve ser caracterizada pela busca da sistematicidade e globalidade do conhecimento: prerrogativa esta inseparável da cientificidade que constitui homenagem plena ao princípio da legalidade. 


\section{A NORMATIVA CONSTITUCIONAL COMO JUSTIFICAÇÃO DA NORMA ORDINÁRIA. PERIGO DA CONSTITUCIONALIZAÇÃO DE TODOS OS RAMOS DO DIREITO E MITIGAÇÃO DAS TRADICIONAIS REGRAS HERMENÊUTICAS. CONTRAPONTO: SIGNIFICADO E EXTENSÃO DO PRINCÍPIO DA LEGALIDADE CONSTITUCIONAL COMO EXIGÊNCIA DE UNIDADE DO ORDENAMENTO E DE SUAS FONTES NORMATIVAS; AS REGRAS HERMENÊUTICAS COMO EXPRESSÃO DA ESTRUTURA E DA LÓGICA DO SISTEMA JURÍDICO, NÃO DA ABSTRATA LÓGICA DO JURISTA}

As normas constitucionais emergem, portanto, como justificação das normas ordinárias, devendo estas se harmonizarem coerentemente e razoavelmente com as primeiras. Há quem diga que isto implica na constitucionalização de todos os ramos do direito, na mitigação das tradicionais regras hermenêuticas e numa notável situação de incerteza jurídica.

É de se observar, entretanto, que cada fase de transformação social e de modificação radical da vida não se caracteriza pela monolítica certeza. Por outro lado, a exigência de atuação do ordenamento constitucional e de interpretação global do ordenamento não encerra em discricionariedade, uma vez que a Carta Fundamental é um ponto firme e, muito embora já se tenha desmentido o mito da certeza do direito, é possível encontrar um ponto de uniformidade na legalidade constitucional, utilizando toda potencialidade do sistema jurídico.

Contudo, a constitucionalização do direito não representa apenas uma exigência de unidade do ordenamento e de respeito à hierarquia de suas fontes normativas, mas também a via praticável para evitar o risco de degeneração do Estado de Direito, quando pensado apenas como exercício de um formalismo-legalista: a Lei Fundamental não garante apenas forma e procedimento, mas compreende também elementos normativos substanciais. Não se trata de destruir, mas sim de adequar interpretação e técnica aos valores constitucionais.

Quanto à mitigação das tradicionais regras hermenêuticas e a notável situação de incerteza jurídica, faz-se necessário ressaltar que se o direito é cultura, é bem verdade que a cultura oficial não pode condicionar a atuação dos valores presentes no 
ordenamento jurídico, o que é condenável quando se pensa que a legalidade constitucional é protetora de valores existenciais, como a tutela da pessoa humana. Ocorre, tão-somente, que a lógica do sistema jurídico não mais se coaduna com a lógica abstrata do jurista.

\section{O PROBLEMA DA DIRETA RELEVÂNCIA DAS NORMAS}

CONSTITUCIONAIS NAS RELAÇÕES INTERPRIVADAS. A APLICAÇÃO INDIRETA VIA NORMA ORDINÁRIA SE TRADUZ, SEGUNDO $O$ ESQUEMA LÓGICO DO COMBINADO / DISPOSTO, EM UMA APLICAÇÃO COMBINADA: NÃO MERA ATIVIDADE INTERPRETATIVA DOS ENUNCIADOS ORDINÁRIOS, MAS ATIVIDADE DE INDIVIDUAÇÃO DA MESMA NORMATIVA

Todavia, a releitura da legislação ordinária à luz das normas fundamentais, na dupla asserção de mera interpretação a partir dos princípios constitucionais e de individuação justificativa da normativa ordinária sob a ótica funcional, não utiliza plenamente as potencialidades das normas constitucionais. Impõe-se enfrentar o problema de sua direta relevância nas relações interprivadas, em particular nas relações de Direito Civil.

Segundo prevalente doutrina alemã, as normas constitucionais devem ser aplicadas às relações civis pela via indireta, ou seja, quando as normas ordinárias são expressas por cláusulas gerais ou mediante o mecanismo da previsão específica e detalhada da fattispecie abstrata pelo legislador. A norma constitucional poderia, então, disciplinar uma relação de Direito Civil mediante aplicação concomitante de uma norma ordinária. Há aqui a aplicação coordenada de uma disposição ordinária segundo o esquema lógico do "combinado disposto". Manifesta-se, portanto, inconsistente a lógica da subsunção que postula erroneamente a precedência lógica da interpretação em relação à qualificação, quando, na verdade, a norma constitucional é parte integrante da normativa destinada a regular o caso concreto.

Assim, as normas constitucionais não traduzem um instrumento subsidiário, 
destinado a regular os casos de lacuna, tal qual sustenta a doutrina majoritária. Pelo contrário, as normas constitucionais - que ditam princípios de relevância geral - são de direito substancial, e não meramente interpretativas; o recurso a estas, mesmo em sede de interpretação, justifica-se, a par de qualquer outra norma, como expressão de um valor em relação ao qual a própria interpretação não pode subtrair-se.

\section{COMPATIBILIDADE DO ASSUNTO COM A EXCLUSIVIDADE ATRIBUÍDA À CORTE CONSTITUCIONAL EM TEMA DE CONTROLE DE CONSTITUCIONALIDADE DOS ATOS COM FORÇA DE LEI E DA SUA POSSIBILIDADE DE ELIMINAÇÃO. UTILIDADE DA NORMA CONSTITUCIONAL NA VALORAÇÃO DISCRICIONÁRIA DO JUIZ E DO INTÉRPRETE. PLANO DIVERSO: CADA UM SE JUSTIFICA POR UMA PRECÍPUA FUNÇÃO}

Dentro do tema da relevância das normas constitucionais nas relações de Direito Civil, a objeção mais séria está centrada na exclusividade atribuída à Corte Constitucional italiana em tema de controle de legitimidade dos atos com força de lei e de sua possibilidade de eliminação. A peculiaridade de tal controle e de seu respectivo procedimento encontra sua causa no interesse geral de eliminação da normativa contrária à Constituição, já que esta surte efeitos erga omnes.

Ao interprete ordinário seria reservada, todavia, a valoração do fundamento da questão. Ao juiz cabe decidir, de maneira discricionária, acerca da dubiedade da conformação constitucional da norma em questão, valendo-se do reenvio à Corte Constitucional; ou se a alegação de ilegitimidade constitucional é manifestamente infundada, seguindo o processo seu curso normal. Entre um caso e outro, o juiz deve decidir se entre a norma ordinária e a norma constitucional existe uma incompatibilidade insanável tal que a aplicação da primeira deriva inevitavelmente na desaplicação do preceito constitucional; ou se a inadequação funcional da norma ordinária é superável em sede interpretativa. Em ambas as hipóteses, o juiz é chamado a pronunciar-se sobre o grau de compatibilidade com as normas constitucionais. 
O interprete, portanto, não pode deixar de utilizar a norma constitucional, ainda que na presença de um mecanismo de controle reservado à Corte Constitucional. Está submetido, contudo, a limitação de que, caso entenda legítima a alegação de inconstitucionalidade ventilada, deve suspender o juízo e reenviar a questão à Corte Constitucional. Logo, trata-se de planos diversos, antes de excluírem-se, cada um se completa em uma relação concreta na qual o interprete ordinário é súdito da legalidade constitucional e responsável pela sua interpretação.

Uma confirmação disso se dá na prática da Corte Constitucional italiana que movimentada pela exigência de evitar vazios no sistema - entre várias interpretações possíveis da normativa ordinária propõe aquela que, ao seu parecer, é constitucional sem que isto constitua um vínculo para todos ou mesmo para o juiz que levantou o incidente de inconstitucionalidade. Também é possível mencionar o caso da Corte de Cassação, que analisa recursos mesmo quando o único fundamento é a falsa aplicação do juiz das normas constitucionais.

Este mecanismo de controle, portanto, não constitui obstáculo para a aplicação das normas constitucionais nas relações concretas, não apenas na ausência de uma precípua normativa ordinária, mas também na presença desta.

\section{CONFIRMAÇÃO DESTA PERSPECTIVA EM ALGUMAS SIGNIFICATIVAS ORIENTAÇÕES JURISPRUDENCIAIS E DOUTRINÁRIAS. ACENO AO DIREITO DO TRABALHO, AO DIREITO PENAL, AO DIREITO PROCESSUAL CIVIL E PENAL. FATTISPECIE CIVILÍSTICA NA UTILIZAÇÃO DIRETA DA NORMA CONSTITUCIONAL SEJA EM PRESENÇA, SEJA EM AUSÊNCIA DE ESPECÍFICA DISCIPLINA ORDINÁRIA}

Uma confirmação desta perspectiva pode ser vista em algumas significativas orientações jurisprudenciais e doutrinárias. No Direito do Trabalho, mesmo podendo valer-se de uma moderna legislação especial, como a contração coletiva, largamente se recorre às normas constitucionais. Já na seara do Direito Processo Civil, mesmo diante 
da ausência de previsão de recurso, tem-se argumentado diretamente com base no texto constitucional, mais precisamente, no exercício do direito de defesa.

Para se limitar a setores que tradicionalmente encontram-se dentro do Direito Civil, é possível mencionar os pronunciamentos dos Tribunais nos casos de adoção, apontando sempre para o princípio do melhor interesse do menor. Aliás, não há como se negar que o Direito de Família abandona a perspectiva patrimonial e agasalha valores existenciais diante, por exemplo: do reconhecimento pleno do direito de manutenção em tema de separação para qualificar o dever do genitor de manter, instruir e educar o filho maior; da releitura do instituto da interdição, admitindo-se algumas disposições de cunho existencial; da superação do catálogo taxativo dos direitos de personalidade em favor de uma cláusula geral de tutela do livre desenvolvimento da pessoa humana; e do reconhecimento da relevância jurídica da família não fundada no matrimônio.

Mesmo o Direito das Obrigações, tido por muitos como uma área impregnada pelo tecnicismo, tem os seus institutos clássicos alterados pela estrutura das relações econômicas e pela ideologia do sistema. Aqui, a incidência das normas constitucionais é direta e fundamental no preenchimento das cláusulas gerais, como boa-fé, ordem pública, causa não imputável, diligência, etc.

Em todas estas situações, a jurisprudência assume a normativa constitucional como parâmetro privilegiado.

\section{RELEVOS CONCLUSIVOS, ÚTEIS À SUPERAÇÃO DA TRADICIONAL CONTRAPOSIÇÃO ENTRE DIREITO PÚBLICO E DIREITO PRIVADO E PARA FUNDAÇÃO DO DIREITO CIVIL-CONSTITUCIONAL}

O que importa não é tanto estabelecer se a aplicação da norma constitucional, aos casos concretos, se dá por via direta ou indireta (distinção nem sempre fácil), mas sim, confirmar a eficácia, com ou sem uma específica normativa ordinária, das normas 
constitucionais frente às relações pessoais e sócio-econômicas. A norma constitucional torna-se a razão justificadora da relevância jurídica de tais relações, constituindo parte integrante da normativa na qual elas, desde um ponto de vista funcional, concretizamse. Portanto, a normativa constitucional não deve ser considerada sempre e somente como mera regra hermenêutica, mas também como norma de comportamento idônea a incidir sobre o conteúdo das relações privadas, subordinadas a novos valores.

Deste modo, a direta relação entre intérprete e norma constitucional tenta evitar a separação desta última do sistema normativo, insistindo na unidade do ordenamento e na superação da distinção entre público e privado. Assim, seria certamente uma limitação arbitrária negar a relevâncias das normas constitucionais nas relações privadas, sobretudo quando estão em jogo direitos fundamentais, entendendo o direito público como um campo de aplicação privilegiado - senão o único - das normas constitucionais.

Apresenta-se, para o civilista, um amplo e sugestivo programa de investigação que se proponha à atuação de objetivos qualificados: individuar um sistema de Direito Civil mais harmonizado aos princípios fundamentais e, em especial, às necessidades existenciais da pessoa; redefinir o fundamento e a extensão dos institutos jurídicos, principalmente, daqueles civilísticos, evidenciando seus perfis funcionais, numa tentativa de revitalização de cada normativa à luz de um renovado juízo de valor (controle de legitimidade); verificar e adaptar as técnicas e as noções tradicionais (da relação jurídica à situação subjetiva, da capacidade de exercício à legitimação, etc.) em um esforço de modernização dos instrumentos e, em especial, da teoria da interpretação.

As indagações apresentadas indicam uma estrada fecunda para a releitura do Direito Civil, contribuindo para a fundação do direito civil-constitucional. É também uma estrada que permite reagir em face do fracionamento do saber jurídico, da excessiva divisão do direito em ramos especializados, que faz do jurista um especialista dotado de conhecimentos técnicos, mas acrítico, insensível ao projeto complexo da sociedade contemporânea. 